UDK 528.94

\title{
ESTIMATION OF THE FRACTURE DENSITY IN RESERVOIR ROCK USING REGRESSION ANALYSIS OF THE PETROPHYSICAL DATA
}

\author{
Mohammad ABDIDEH \\ Department of Petroleum Engineering, Omidiyeh Branch, Islamic Azad University, Omidiyeh, Iran \\ E-mail:m.abdideh@yahoo.com
}

Received 29 May 2016; accepted 12 September 2016

\begin{abstract}
Image logs are presently the main specialized tools for fracture detection in hydrocarbon reservoirs. Where image logs are not available, other less rewarding substitutes such as isolated well tests and type curve analysis, drilling mud loss history, core description and conventional petrophysical logs are used for fracture detection. In this paper a novel method is proposed for fracture density estimation in the fractured zones, using energy of petrophysical logs. Image and petrophysical logs from Asmari reservoir in one well of an oilfield in southwestern Iran were used to investigate the accuracy and applicability of the proposed method. Energy of the petrophysical logs in the fractured zones is calculated and linear and non-linear regressions between them are estimated. Results show that there is strong correlation between the energy of caliper, sonic (DT), density (RHOB) and lithology (PEF) logs with fracture density in well. In order to find a generalized estimator, a unique normalization method are developed, and by using it, a non-linear regression has been found which estimates fracture density with correlation coefficient of higher than $85 \%$. The resultant regression has the capability of generalization in the studied field.
\end{abstract}

Keywords: fracture density, petrophysical data, well logging, reservoir rock, regression analysis.

\section{Introduction}

Almost all hydrocarbon reservoirs are influenced by natural fracture in one way or the other. However, the role and behavior of fractures in the reservoirs are not recognized well. One of the most important effective factors in producing oil reservoirs is the permeability that this factor has a direct relation to the fractures in the reservoir rock.

Generally, determining density, strike and dip direction, aperture width, distance of fractures, and finally providing suitable pattern from reservoirs fractures extensively helps in the planning, development, and production of oil fields. One of the most important resources for studying reservoirs is cores. Unfortunately, for various reasons, many boreholes are without a core or cores due to their low recovery and are not very usable. The latter is true especially in fractured carbonate reservoirs in southwestern Iran. Furthermore, due to unknown core orientation, determining strike and dip direction of structures, such as bedding, fractures, probable faults, and cross-bedding, is impossible.

Natural fractures have significant influence on the reservoir behavior and performance. Therefore, in modeling fractured reservoirs, understanding fracture properties is very important (Roehl, Choduette 1985). Fractured zones can probably be detected both directly and indirectly using seismic sections, petrophysical logs, well tests, drilling mud loss history and core description (Thompson 2000; Nelson 2001; MartinezTorres 2002; Dutta et al. 2007; Tokhmechi et al. 2009a, 2009b). However, each of these methods is subjected to some limitations in practice.

Since mid 1980s, and introduction of dip meter technology and image logs, the process of fracture detection and characterization of fracture properties; such as dip, dip direction, fracture density and opening; has become less problematic (Serra 1989). Presently, these high resolution data acquisition devices can detect small scale variations and discontinuities in rocks. Unfortunately, no image log is available for thousands of wells drilled before introduction of these new technologies.

As fractures modeling with an inadequate volume of data can lead to misleading interpretations, any direct or indirect techniques which increase the knowledge of fracture properties is highly valuable. In general, fracture modeling is an object based practice 
which requires a larger amount of data, compared to pixel based modeling, because of dividing data in some object sets in object based modeling, where each set is separately used in modeling.

Earlier attempts to detect natural fractures include the use of sonic waves (Hsu et al. 1987), wavelet transform (Daiguji et al. 1997), a so called velocity deviation log (Flavio, Gregor 1999), core data (Song et al. 1998) and seismic data (Behrens et al. 1998). In a recent attempt, wavelet transform was applied on porosity log data and it was suggested that high frequency variations correspond to the existence of fractures (Sahimi, Hashemi 2001). To validate the model, permeability data were used, where large increases in permeability correspond to the existence of fractures. Surjaatmadja et al. (2002) used a frequency decomposition approach to analyze downhole data to detect natural fractures. Martinez-Torres (2002) applied a fuzzy logic technique to various petrophysical logs, while a classification algorithm was used by Tran (2004) to study and detect natural fractures. Shen and Li (2004) have presented a combined approach for characterization of naturally fractured reservoirs. Application of shear-wave technique to identify fault zones (Dutta et al. 2007), a wavelet transform applied to petrophysical logs (Mohebbi et al. 2007), factor analysis to detect open fractures near faults (Ozkaya, Siyabi 2008) and detecting fracture corridors using probabilistic decision trees (Ozkaya 2008) are other methods used by other researchers to identify and characterize natural fractures. Yan et al. (2009) presented a method to model fracture porosity. They used petrophysical logs in order to create a synthetic image log. Proposed method was checked in a well of a gas saturated carbonate reservoir. This study revealed that it is possible to identify fractures location and some of their properties.

In this paper a method has been presented to estimate fracture density in fractured zones. All available conventional petrophysical logs have been used in proposed methodology. Simple linear and non-linear estimators have been used in order to develop an equation with high generalization capability. The proposed methodology has been applied to one vertical well in an oilfield located in the southwest Iran, where sequences of fractured zones with variable fracture density is observed along with non-fractured intervals in the Oligo-Miocene Asmari carbonate Formation (Alavi 2004). A large volume of data has been used in this analyzes, which enables us not only to check the accuracy of the method, but also to study the possibility of its generalization.

\section{Methods and materials}

In this section, two techniques and data used in this study have been briefly presented.

\subsection{Petrophysical logs energy}

Calculation of petrophysical logs energy is a simple procedure that magnifies the differences between log data. The following procedure has been used to calculate petrophysical log energy for each log:

- Select suitable logs for each well.

- Identify fractured zones in well using petrophysical logs.

- Calculate petrophysical log energy $\left(E_{P L}\right)$ for each fractured zone using Eq. (1):

$$
E_{p L}=\sum_{i=1}^{n} P L_{i}^{2}
$$

where $P L$ and $n$ are the amount of petrophysical $\log$ and the number of petrophysical log in each fractured zone respectively.

- Assign the result of part $c$ for each fractured zone.

In the end of the procedure a new log is created which the number of its members is equal to the number of fractured zones in studied well. This log is named energy log in this paper.

\subsection{Normalization of the energy logs}

Normalization of energy log follows the following algorithm:

- Calculate mean of energy log in each well:

$$
M E_{P L}=\frac{\sum_{j=1}^{c} E P j \cdot n j}{\sum_{j=1}^{c} n j},
$$

where $M E_{P L}$ is the mean of energy log of certain petrophysical $\log$ in well. $E_{P L j}$ and $n_{j}$ are as the same as Eq.(1) in each fractured zone. $\mathrm{C}$ is the number of fractured zones in each well.

- Calculate the mean of energy $\log \left(M Z E_{P L j}\right)$ in each zone:

$$
M Z E_{P L}=M E_{P L} \cdot p_{i} .
$$

The amounts of $M Z E_{P L j}$ depend on petrophysical logs, but their variation is independent of petrophysical logs. Therefore it is a unique normalization method because normalized numbers depends to fractured zones thickness and mean weighted values of various petrophysical logs in fractured zones.

More than 300 wells are drilled in the studied field. Whole suit of conventional logs including caliper, Density, 
Neutron, Sonic, resistivity and natural gamma ray spectrometry ran in most of them whereas image logs ran in only one well. There are some probabilistic methods that can help identifying fractured zones in the wells without image logs. As the studied reservoir is a naturally fractured formation, estimating fracture density in fractured zones using petrophysical logs helps generating valuable data for about 300 wells. Petrophysical logs and interpreted image logs of the studied well were used to generate an estimator of fracture density in fractured zones which can be generalized to all wells. Fractured zones and the number of fractures in each fractured zone (fracture density) are identified from interpretation of image logs.

\section{Discussion}

This approach will be useful if a generalized correlation between energy log and fracture density in each fractured zones can be established.
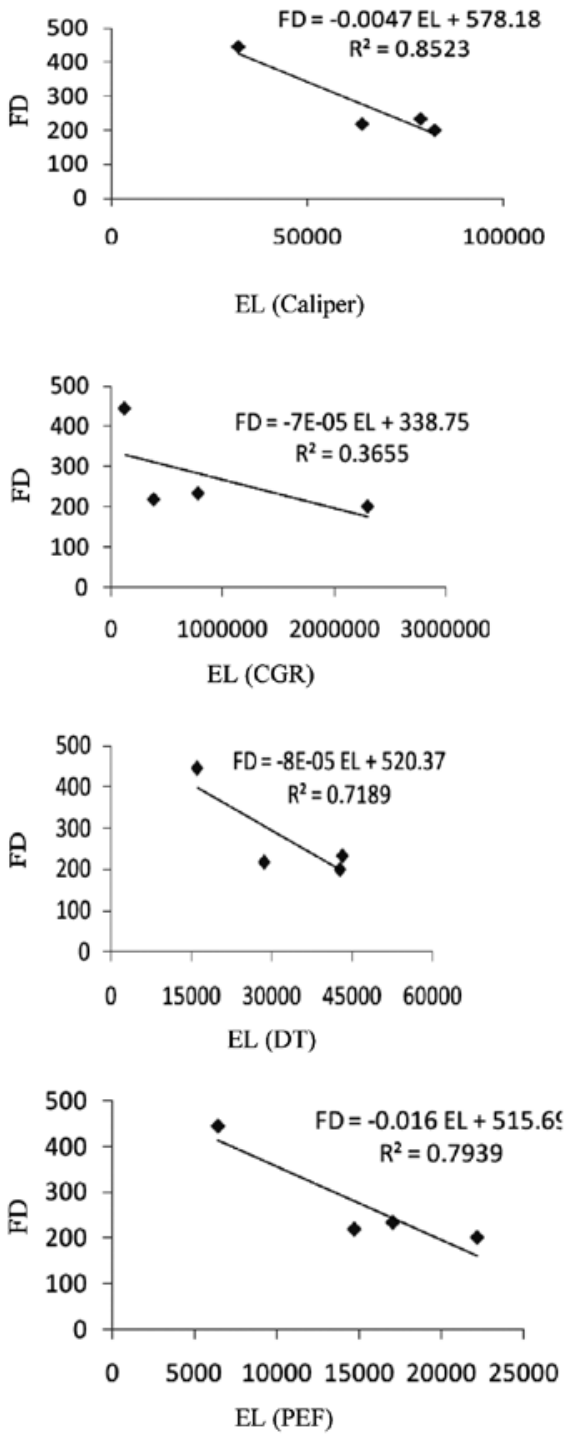

\subsection{Correlation between energy log and fracture density}

Good linear regression is observed between energy log of some of the petrophysical logs and fracture density in fractured zones of well. Regressions in well are shown in Figure 1. As it can be seen in this figure, correlation coefficient for caliper, DT, RHOB and PEF are higher than 0.71 . Therefore it is clear that estimation of fracture density in fractured zones using those petrophysical logs leads to accurate prediction of fracture density and named petrophysical logs were selected for generalization stage. The fracture density in each fractured zone and selected petrophysical logs of well are shown in Figure 2.

Energy log data of selected petrophysical logs of the studied well are gathered together to investigate linear or non-linear regression between energy log and fracture density. The results are shown in Figure 3.
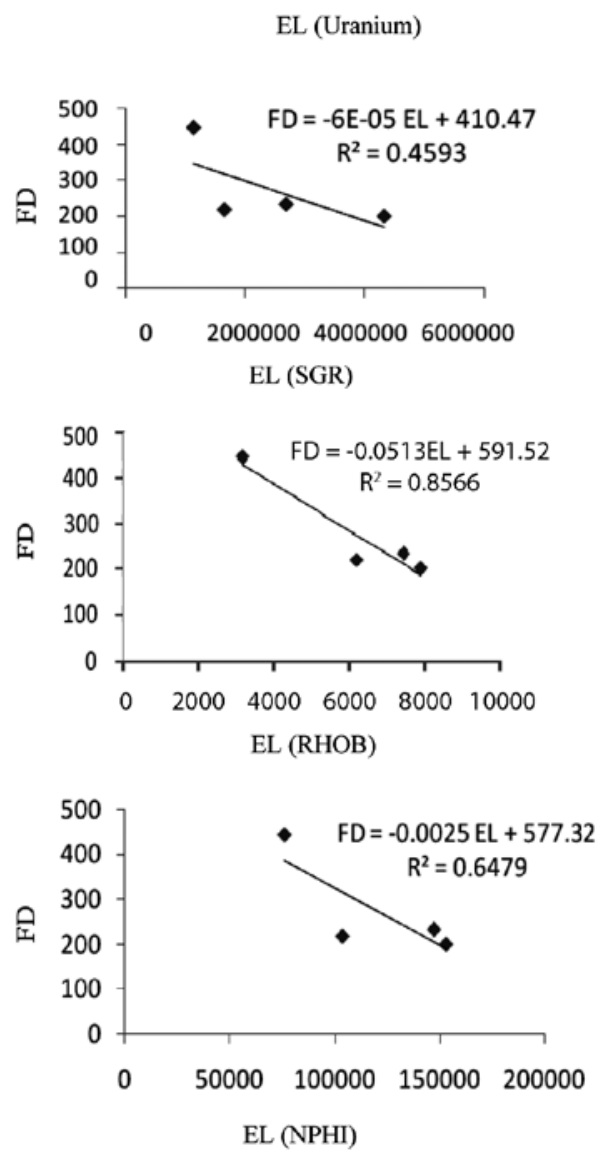

Fig. 1. Linear regression between energy log and fracture density in the fractured zones for well 


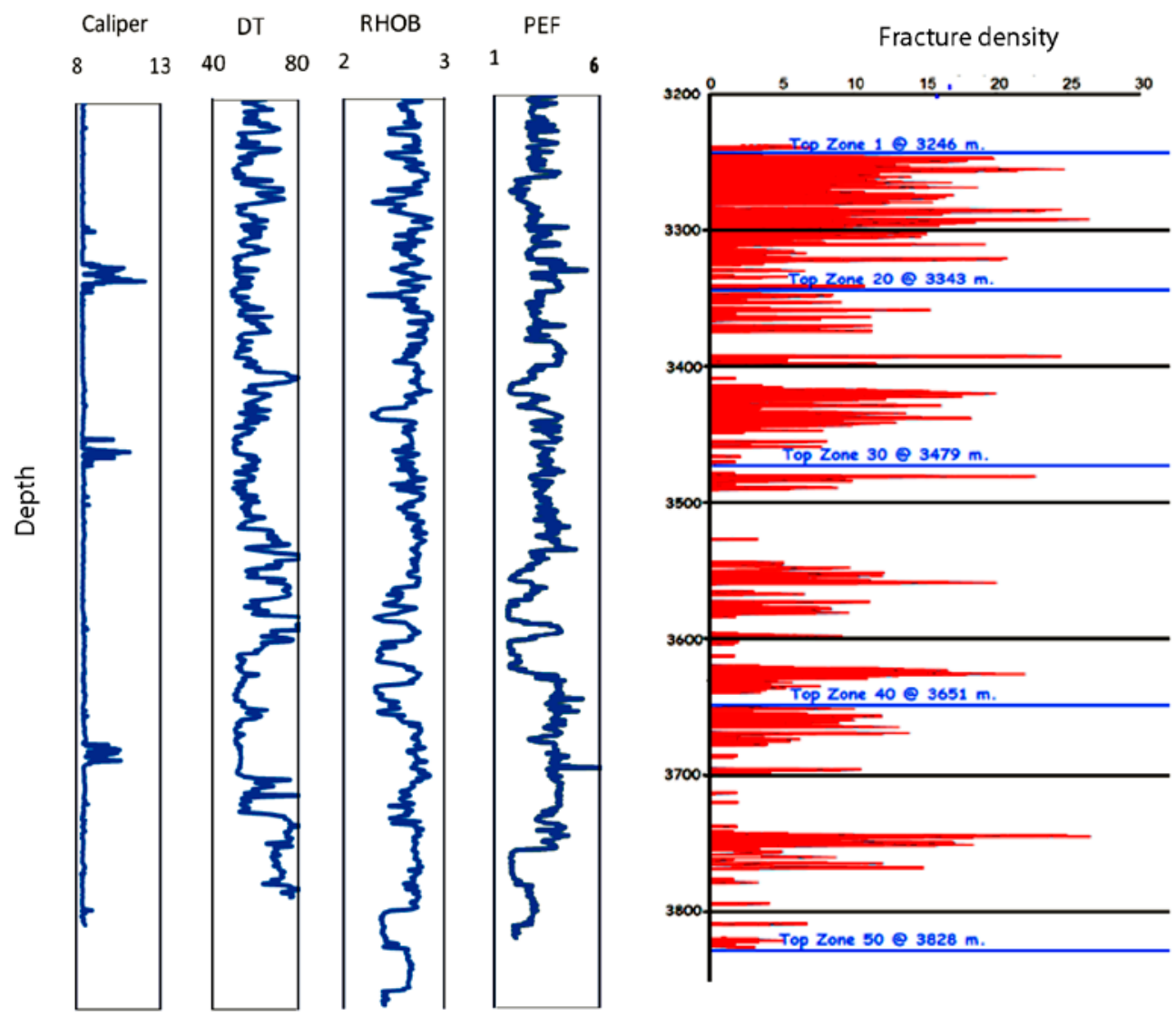

Fig. 2. The fracture density in each fractured zone and selected petrophysical logs for well
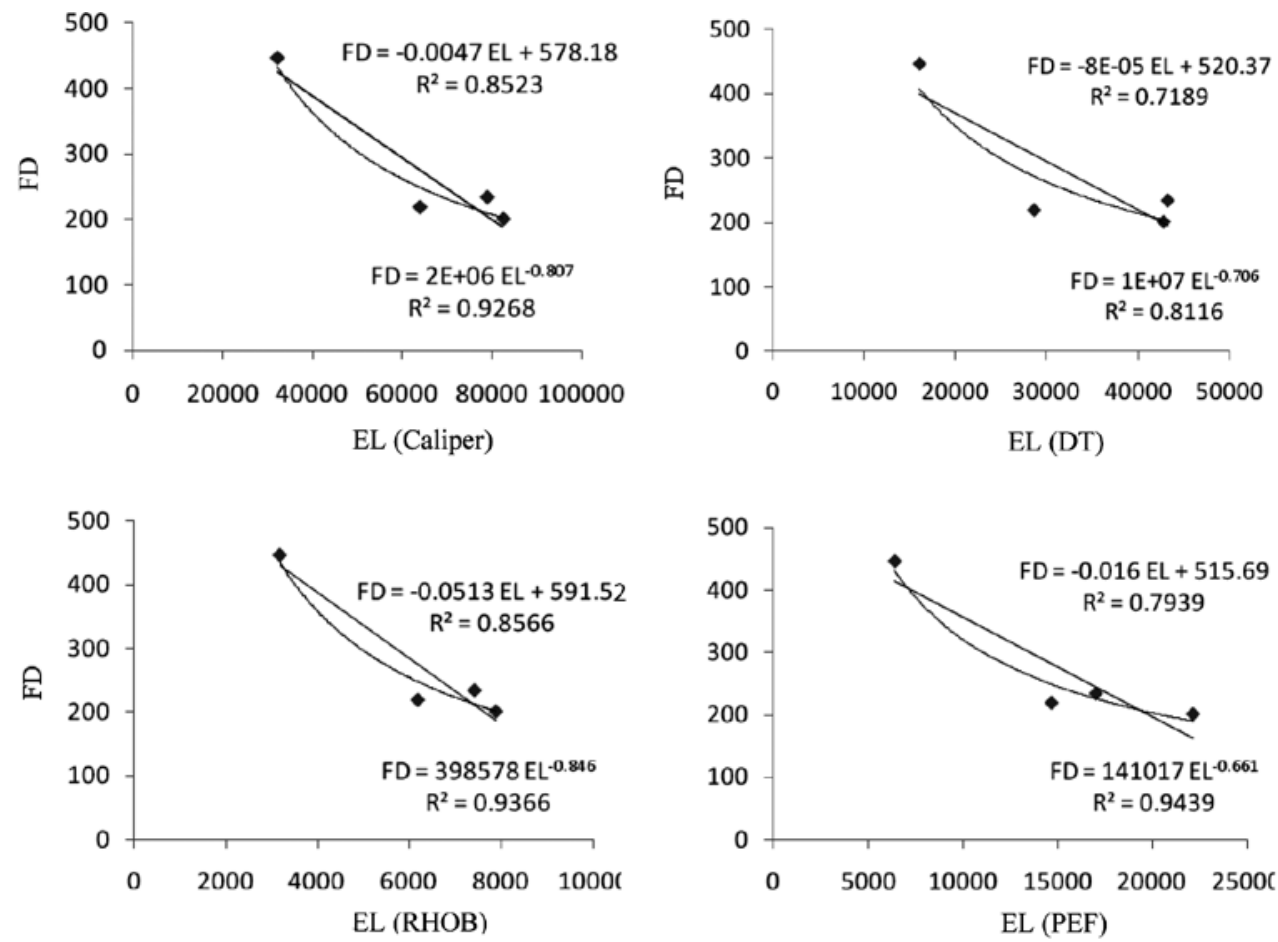

Fig. 3. Linear and non-linear regression between energy log and fracture density in fractured zones of studied well 
According to the results, no strong linear or nonlinear regression is observed. Only coefficient correlation of non-linear regression of caliper and RHOB are higher than 0.75. Although these two correlations are not poor, but they are less than 0.8 , indicating that estimation is not reliable. Therefore we should generate other regressions with better correlation.

\subsection{Generating better generalized regressions}

Figure 3 shows that in generalization stage, fitness of simple nonlinear regression to data is better than linear regression. Therefore, a new generalized simple non-linear regression with higher correlation coefficient should be found. For this purpose, energy log data of well are accumulated and normalized using Eqs (2) and (3).

As mentioned before, normalized data merely depend on the thickness of fractured zones and are independent of the type of petrophysical logs.

Non-linear regression between normalized energy $\log (\mathrm{NEL})$ and fracture density in one studied well for four selected petrophysical logs is shown in Figure 4. As it can be seen in this figure, the correlation coefficients of non-linear regressions are higher than 0.91 and independent from petrophysical logs.

The figures of four non- linear regressions are similar, but their coefficients differ, because they just depend on the $M E_{P L}$ (Eq. (2)).
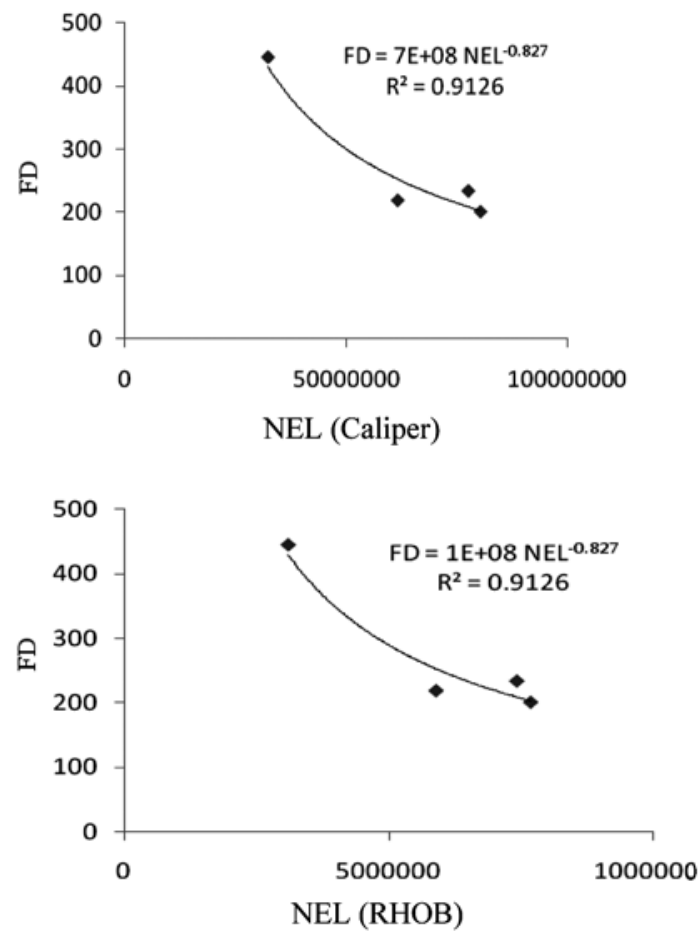

As it can be seen in Figure 4, the parametric figure of non-linear regression equations show a general form of:

$$
F D=a \cdot N E L^{b}
$$

Where $a$ and $b$ are constant and depend on the mean of fracture density and mean of energy log in each zone. The simple way for definition $a$ and $b$ is converting an exponential curve to a linear one, using the following algorithm:

$$
\begin{gathered}
\log (F D)=\log \left(a \cdot N E L^{b}\right) \rightarrow \log (F D)= \\
\log (a)+b \log (N E L)
\end{gathered}
$$

This expresses that $\log$ (fracture density) is a linear function of $\log (N E L)$, where $b$ is line slope and $\log (a)$ is intercept. Therefore, if we find the best fit line, using $\log$ (fracture density) as a function of $\log (N E L)$, fracture density can obtained. Of course, there is another tentative way for defining a and b. Slope a is defined as follows:

$$
a=\frac{M F D}{M E L \cdot 26.58}
$$

Where MFD is the mean of fracture density in each fractured zone and MEL is the mean of energy $\log$ in the resolution thickness of petrophysical logs $(0.1262 \mathrm{~m})$. The coefficient 26.58 is calculated using numerical optimization of estimation with the aim of minimizing error. Based on these parameters, calculation of coefficient a is very simple.
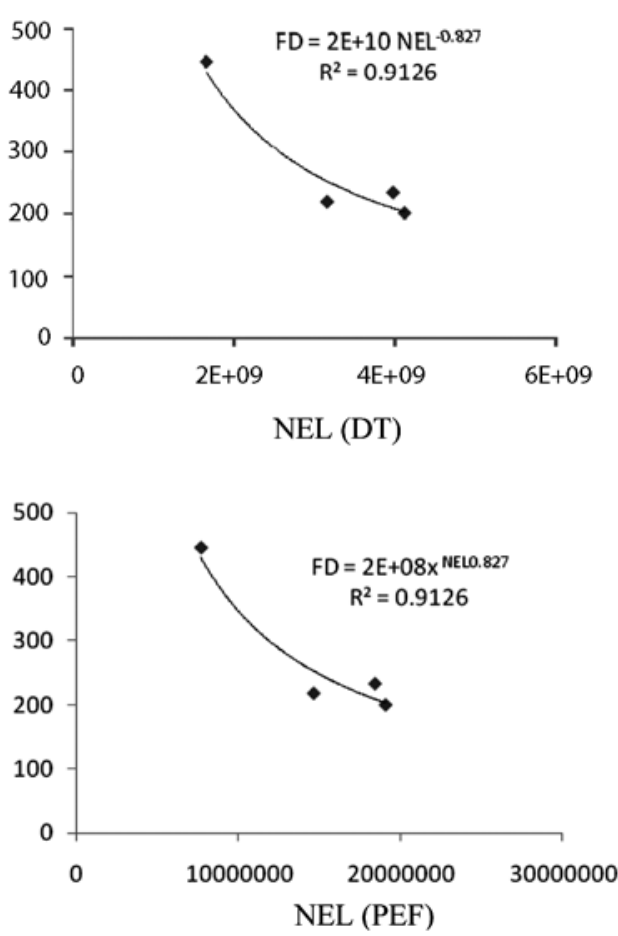

Fig. 4. Non-linear regression between NEL and fracture density in fractured zones of studied well 
Power $b$ just depends to MFD and it is independent of energy log. Therefore it is constant for various petrophysical logs. $b$ can be calculated using the following equation:

$$
b=\mathrm{MFD} \times 0.08,
$$

where 0.08 is a constant coefficient and independent from studied data. For example, as it can be seen in Figure $4 \mathrm{~b}$ remains constant with changing the petrophysical logs. In Figure $4 \mathrm{~b}$ approaches to one, which means non-linear regression approaches to a linear one.

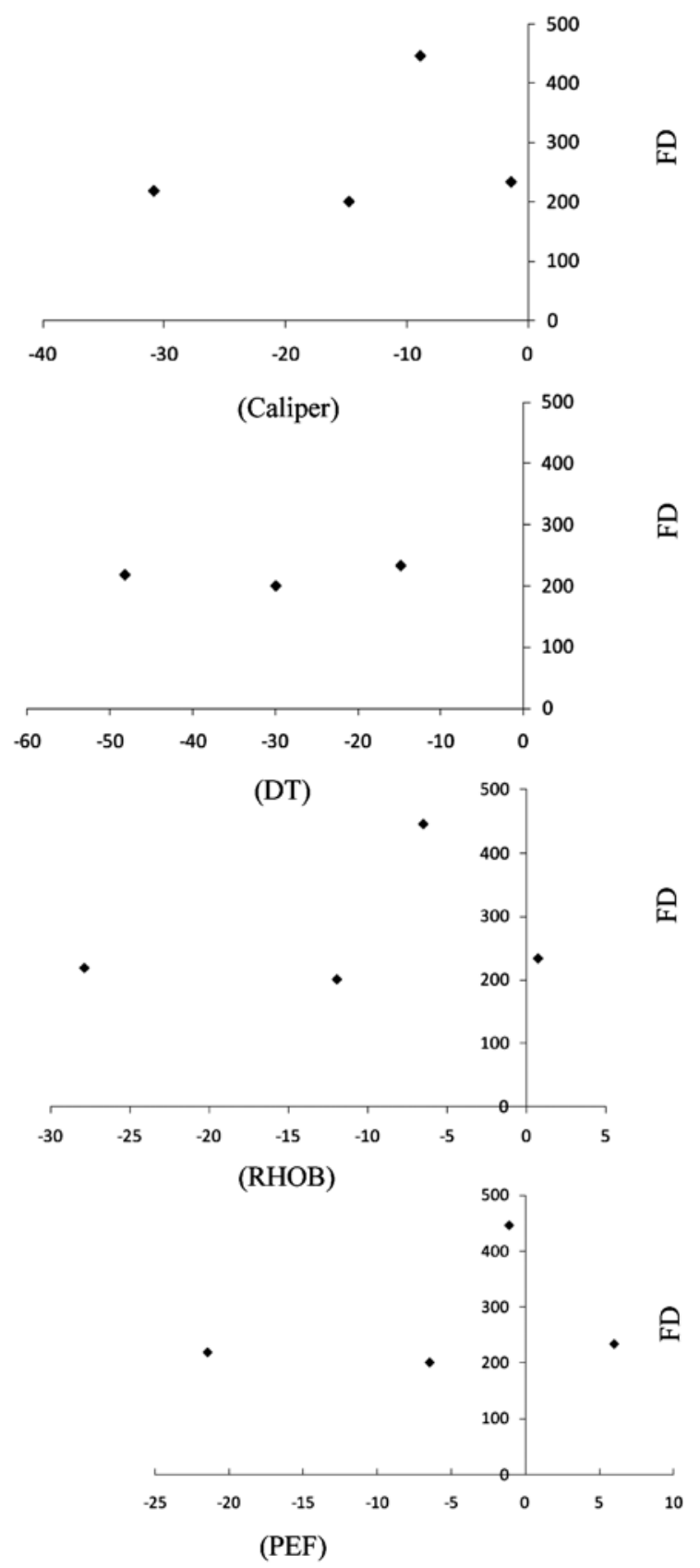

Fig. 5. Error of estimation fracture density using caliper, sonic (DT), density (RHOB), lithology (PEF) log, and Eq. (4) in the studied well
It is clear that the error of estimation, which is the difference between the number of fractures in each fractured zone find in image log minus the estimated number of fractures; varies for various petrophysical logs. This is because slope a depends on the MEL. According to the results, lithology log (PEF) is the best petrophysical log with the least error for fracture density estimation (Fig. 5). In this figure, error is increased with increasing the energy log corresponds with increasing the thickness of fractured zones.

\section{Conclusions}

This paper proposes a method to estimate fracture density in fractured zones using petrophysical logs. High volume of the data used in this study is one of the points of strength which can support the validity of the results. Image logs of one well in an Iranian oil field were used in order to identify fractured zones and fracture density. Petrophysical logs of the well are used for estimation of fracture density in fractured zones. Energy logs and NELs are calculated as the base data of estimation. In order to find better generalized estimator, NEL is calculated and non-linear regression is utilized. In conclusion, the findings of this paper are:

It is possible to fit linear regressions between energy log and fracture density in each well separately.

For this purpose four petrophysical logs, caliper, sonic (DT), density (RHOB) and lithology (PEF), are more suitable.

The arithmetic average correlation coefficient of linear regression between energy log and fracture density in the studied well for caliper and lithology logs is about $86 \%$, which indicates existence of high correlation between them.

A simple power regression is established which as an unbiased estimator approximate fracture density in fractured zones with about 0.913 correlation coefficient.

\section{References}

Alavi, M. 2004. Regional stratigraphy of the Zagross fold-thrust belt of Iran and its proforeland evolution, American Journal of Science 304: 1-20. http://dx.doi.org/10.2475/ajs.304.1.1

Behrens, R. A.; Macleod, M. K.; Tran, T. T.; Alimi, A. O. 1998. Incorporating seismic attribute maps in 3D reservoir model, SPE Reservoir Evaluation \& Engineering 1: 122-126. http://dx.doi.org/10.2118/36499-PA

Daiguji, M.; Kudo, O.; Wada, T. 1997. Application of wavelet analysis to fault detection in oil refinery, Computers \& Chemical Engineering 21(suppl.): S 1117-S 1122.

Dutta, P.; Singh, S. K.; Al-Genai, J.; Akhtar, A.; Akbar, M. 2007. A novel approach to fracture characterization utilizing 
borehole seismic data, in 15th SPE Middle East Oil \& Gas Show and Conference, 11-14 March, Manama, Bahrain. Paper SPE, 105427.

Flavio, S. A.; Gregor, P. E. 1999. The velocity-deviation log a tool to predict pore type and permeability trends in carbonate drill holes from sonic and porosity or density logs, American Association of Petroleum Geologists Bulletin 83(3): 450-466.

Hsu, K.; Brie, A.; Plumb, R. A. 1987. A new method for fracture identification using array sonic tools, Journal of Petroleum Technology 39(6): 677-683. http://dx.doi.org/10.2118/14397-PA

Martinez-Torres, L. P. 2002. Characterization of naturally fractured reservoirs from conventional well logs: MSc Thesis. University of Oklahoma. USA.

Mohebbi, A. R.; Haghighi, M.; Sahimi, M. 2007. Using conventional logs for fracture detection and characterization in one of Iranian field, in International Petroleum Technology Conference, 4-6 December 2007, Dubai, UAE. Paper IPTC, 11186.

Nelson, R. A. 2001. Geologic analysis of naturally fractured reservoirs. 2 ed. Gulf Professional Publishing, U.S.A. 332 p.

Ozkaya, S. I. 2008. Using probabilistic decision trees to detect fracture corridors from dynamic data in mature oil fields, SPE Reservoir Evaluation \& Engineering 11(6): 1061-1070. http://dx.doi.org/10.2118/105015-PA

Ozkaya, S. I.; Siyabi, S. 2008. Detection of fracture corridors from dynamic data by factor analysis, in SPE Saudi Arabia Section Technical Symposium, 10-12 May 2008, Al-Khobar, Saudi Arabia. Paper SPE, 120812.

Roehl, P. O.; Choduette, P. W. 1985. Carbonate petroleum reservoirs. New York: Spring-Verlag. 622 p. http://dx.doi.org/10.1007/978-1-4612-5040-1

Sahimi, M.; Hashemi, M. 2001. Wavelet identification of the spatial distribution of fractures, Geophysical Research Letters 28(4): 611-614. http://dx.doi.org/10.1029/2000GL011961

Serra, O. 1989. Formation MicroScanner image interpretation. Schlumberger Education Services.

Shen, F.; Li, S. 2004. A combined geological, geophysical and rock mechanics approach to naturally fractured reservoir characterization and its applications, in SPE Annual Technique Conference and Exhibition, 26-29 September 1989, Houston, Texas. Paper SPE, 90275. 8 p.

Song, X.; Zhu, Y.; Iiu, Q.; Chen, J.; Ren, D.; Li, Y.; Wang, B.; Liao, M. 1998. Identification and distribution of natural fractures, in SPE International Conference and Exhibition in China, 2-6 November, Beijing, China. Paper SPE, 50877.

Surjaatmadja, J. B.; Stephenson, S.; Cheng, A. 2002. Analysis of generated and reflected pressure waves during fracturing reveals fracture behavior, in SPE Annual Technical Conference and Exhibition, 29 September - 2 October 2002, San Antonio, Texas. Paper SPE, 77598. http://dx.doi.org/10.2118/77598-MS

Thompson, L. B. 2000. Fractured reservoirs: integration is the key of optimization, Journal of Petroleum Technology 52(02): 52-54. http://dx.doi.org/10.2118/56010-JPT

Tokhmechi, B.; Memarian, H.; Noubari, H. A.; Moshiri, B. 2009a. A novel approach proposed for fractured zone detection using petrophysical logs, Journal of Geophysics and Engineering 6: 365-373. http://dx.doi.org/10.1088/1742-2132/6/4/004

Tokhmechi, B.; Memarian, H.; Rasouli, V.; Noubari, H. A.; Moshiri, B. 2009b. Fracture detection from water saturation $\log$ data using a Fourier-Wavelet approach, Journal of Petroleum Science and Engineering 69(1-2): 129-138. http://dx.doi.org/10.1016/j.petrol.2009.08.005

Tran, N. H. 2004. Characterization and modeling of naturally fractured reservoirs: PhD Thesis. University of New South Wales, Australia.

Yan, J.; Lu, L.; Lubbe, R.; Payne, S. 2009. Petrophysical fracture identification for rock physics studies, in $71^{\text {st }}$ EAGE Conference \& Exhibition, 8-11 June 2009, Amsterdam, The Netherlands. 5 p. http://dx.doi.org/10.3997/2214-4609.201400200

Mohammad ABDIDEH. PhD in Geology, Associate Professor. Department of Petroleum Engineering, Omidiyeh Branch, Islamic Azad University, Omidiyeh, Iran. Research interests: petroleum geology, geostatistical modeling, petrophysics, rock mechanics, formation evaluation. 